\title{
An Audit of Mechanized Road Sweeping Operations in National Capital of India- A case Study
}

Sourabh Manuja

Fellow, Environment and Waste Management Division, The Energy and Resources Institute, Indian Habitat Centre, Lodhi Road, New Delhi-110003, India

Kuldeep Choudhary

Project Consultant, Environment and Waste Management Division, The Energy and Resources Institute, New Delhi-110003, India

\author{
Akash Upadhyaya \\ Project Consultant, Environment and Waste Management \\ Division, The Energy and Resources Institute, \\ New Delhi-110003, India \\ Suneel Pandey \\ Director, Environment and Waste Management Division, \\ The Energy and Resources Institute, Indian Habitat Centre, \\ Lodhi Road, New Delhi-110003, India
}

health organization (WHO) revealed that around 4.2 million deaths occur every year due to outdoor air pollution, demonstrating a share of $7.6 \%$ of all mortality in 2016 [2]. This mortality is due to exposure to small particulate matter of 2.5 microns or less in diameter (PM2.5), which cause cardiovascular and respiratory disease, as well as cancer [3]. The impact of air pollution is not only limited to health but extends to agriculture and the general well-being of humans, floral and faunal population [1].

The 2005, WHO air quality guidelines indicated, that by reducing particulate matter of 10 microns or less in diameter $\left(\mathrm{PM}_{10}\right)$ concentrations from 70 to 20 micrograms per cubic meter $\left(\mu \mathrm{g} / \mathrm{m}^{3}\right)$, air pollution-related deaths can be reduced by around $15 \%$. Similarly, by reducing annual average $\mathrm{PM}_{2.5}$ concentrations from levels of $35 \mu \mathrm{g} / \mathrm{m}^{3}$ (common in many developing cities), to $10 \mu \mathrm{g} / \mathrm{m}^{3}$, air pollution-related deaths can be reduced by around $15 \%$, establishing linkage and need for clean air worldwide [4].

In 2018, the WHO global air pollution database revealed that India had 14 out of the 15 most polluted cities in the world [5]. In India, data generated from National Air Quality Monitoring Programme (NAMP) over the years reveal that particulate matters $\left(\mathrm{PM}_{10}\right.$ and $\left.\mathrm{PM}_{2.5}\right)$ are the major challenge, found to be exceeding the National Ambient Air Quality Standard (NAAQS) all across the country-more specifically in urban areas of Indo-Gangetic plain [1]. Studies in past spread over 2007-2010 conducted for Bengaluru, Chennai, Delhi, Kanpur, Mumbai and Pune reveled that dust from road dust re-suspension, construction activities, and soil has the major contribution $(6 \%-58 \%)$ to $\mathrm{PM}_{10}$ concentrations. Source apportionment studies for Delhi by Central pollution control board in 2010 reveled that road dust contributed to about $14.5 \%$ - 29\% to $\mathrm{PM}_{10}$ pollutant loads [6]. A study in 2015 for Delhi identified that road dust and soil contributes $14.4 \%$ and $26.5 \%$ in $\mathrm{PM}_{10}$ and $4.3 \%$ and $27.1 \%$ in $\mathrm{PM}_{2.5}$ pollutant load in winter and summer respectively [7]. Further, a study in 2018 revealed, dust and construction contribute $17 \%$ and $38 \%$ of $\mathrm{PM}_{25}$ concentrations and $25 \%$ and $41 \%$ of $\mathrm{PM}_{10}$ concentration in Delhi during summer and winters respectively [8]. Indicating a clear need to reduce exhaust and non-exhaust emissions resulting in current 
particulate matter emission levels, from the city- particularly associated with roads dust [9]. In 2019 Delhi's PM $_{2.5}$ average were reported as $98.6 \mu \mathrm{g} / \mathrm{m}^{3}$, which was much higher compared to WHO targets [10].

In the era where mechanization and automation are the new norms for urban services - due to increasing development and requirements of clean air, mechanization of road sweeping is growing worldwide. Mechanized Road Sweeping (MRS) machines are certified as $\mathbf{P M}_{10}$ efficient or capable of a picking up greater than or equal to $80 \%$ of $\mathrm{PM}_{10}$ particles which is stirred up from vehicular traffic on paved roadways [11]. Indore, a city in state of Madhya Pradesh in India reported a drop in $\mathrm{PM}_{10}$ and $\mathrm{PM}_{2.5}$ by $8.3 \%$ and $5 \%$ respectively from 2018 in 2019 due to MRS operations [12]. Indore also claimed that after using mechanical road sweepers, respirable suspended particulate matter (RSPM) level of city were reduced from 145 $\mathrm{mg} / \mathrm{Nm} 3$ to $75-80 \mathrm{mg} / \mathrm{Nm} 3$ and as an impact respiratory Air borne diseases were reduced by $70 \%$ [13]. Demand for better cleanliness vis-à-vis limited availability of human workforce and high labor costs around the world are other reasons, pushing MRS operations in developed and developing countries [14].

However, MRS machines, are not only a costly investment for an urban local body (ULB), but a gigantic task to efficiently operate a fleet of such machines. Till recent past, there has been no study on optimum utilisation of these machines, and setting up monitoring, review and verification mechanisms to optimise its operations. Central Public Health and Environmental Engineering Organisation (CPHEEO) a technical wing of Ministry of Housing and Urban Affairs (MoHUA) has given guidelines to operate these machines in double shift, looking into the cost of these machines [15], but guidelines for operation and effective utilisation of these machines is still not developed for ULBs.

This paper captures the findings of audits capturing MRS operations for all four ULBs of Union territory of Delhi East Delhi Municipal Corporation (EDMC), New Delhi Municipal Council (NDMC), North Delhi Municipal Corporation (North DMC), and South Delhi Municipal Corporation (SDMC). The objective of this paper is to make policy makers, city managers, consultants, technocrats, and other related stakeholders realise the need of such performance audits and help in establishing monitoring, review and verification (MRV) systems for other ULBs around the world using MRS machines to make their operations more efficient and effective.

\section{MATERIAL AND METHODS}

The basic services in Union Territory of Delhi are managed by four Municipal Corporation. Delhi has 1100 $\mathrm{kms}$ of roads with $30 \mathrm{~m}$ or more right of way [16], totaling to $4400 \mathrm{kms}$ of road stretch to be swept. With $10 \mathrm{MRS}$ machines in EDMC, 7 MRS machines in NDMC, 18 MRS machines in North DMC and 24 MRS machines in SDMC, Delhi has in total 59 truck mounted MRS machines operating on roads as reported till early 2020.

All the ULBs own these machines and contract out their operations to private parties in varied manner. EDMC and
North DMC provide comprehensive operations and maintenance contracts for MRS operation. SDMC contracts out operations and minor maintenance, and keeps major maintenance and spares under its ambit. NDMC only hire drivers and operators for MRS operations through contracts, keeping minor and major maintenance for these machines under its ambit. Fuel (Diesel) and water to these machines are provided by respective ULBs.

All the MRS machines are truck mounted and have vacuum suction engines (auxiliary engine). Machines have side and central brushes and sprinklers on sides (above the brushes) and in front. Few machines also have sprinklers at back side of the machine, with a purpose to suppress suspended dust (during broom operation) through water mist. These machines are capable of sweeping one side and central bush of the road at a time, and require trained staff for its operations. These MRS machines are either operated with dry or wet sweeping mechanism. EDMC has all dry sweeping machines which has 30 number of particulate matter arresting filters in each machine, SDMC has 18 dry sweeping machines and North DMC has 12. NDMC has 2 dry sweeping machines which have been modified by removing filters. These filters require deep cleaning after every 4 weeks of operation to make sweeping operations effective. The new machines in SDMC and North DMC and rest of the machines in NDMC are wet sweeping machines which act like wet scrubbers to arrest and keep the collected road dust inside them. The dust holding capacities are 6.5cum for dry sweeping and 4.5cum for wet sweeping MRS machines.

All the corporations track their MRS machines through Global Positioning System (GPS) trackers. These GPS trackers provide information about the routes covered, distance travelled, hours of operation of auxiliary engines, current location of machine, etc. They even track the speed of machines on particular routes to inform monitoring staff about its operations. But, these GPS systems do not track if sweeping was undertaken on particular route travelled, or if sprinkling was done and sweeping was effective, or if machine operated its brush or not while moving on a stretch. It also does not track the reasons for machine standing idle on a particular location or delay in operation. Therefore, the corporations wanted to assess the operations of these MRS machines and make them more effective and efficient, as the corporations did not had an appropriate MRV system set in place for evaluating MRS operations.

Thus, to oversee MRS operations and identify lacunae which need to be addressed to make operations more efficient, independent third party audits of these machines were undertaken by the corporations engaging The Energy and Resources Institute (TERI). These audits were designed to collect data on (a) time spent by these machines on various on-shift activities (stated in table 1), (b) evaluate the actual kilometers of sweeping undertaken per shift by each machine and (c) ways to improve sweeping outputs every shift. 
TABLE 1: ON-SHIFT ACTIVITIES UNDERTAKEN DURING MRS OPERATION

\begin{tabular}{|c|c|c|}
\hline S.N. & On shift activity & Description \\
\hline 1. & Sweeping & The actual road sweeping operation \\
\hline 2. & Travelling & $\begin{array}{l}\text { Travelling from stationed depot to work area (route) or one route to another, or from route to } \\
\text { dumping station. }\end{array}$ \\
\hline 3. & Dumping & Time involved in dumping the collected road dust at the designated location \\
\hline 4. & Maintaining & Time spent in case of breakdown of a machine/ nozzle cleaning during the shift operation \\
\hline 5. & Refilling water & Time spent during shift on water refiling \\
\hline 6. & Refilling diesel & Time spent during shift on Diesel refilling \\
\hline 7. & Purging & $\begin{array}{l}\text { During operation the filters are required to be backwashed with air to release the clogged pores. } \\
\text { The time spent under this activity is noted under purging }\end{array}$ \\
\hline 8. & $\begin{array}{l}\text { Waiting for starting } \\
\text { work }\end{array}$ & $\begin{array}{l}\text { Before the operations start many time staff have to wait for either getting the route for the day / for } \\
\text { some staff to arrive. The time spent during shift is recorded under this activity. The rainy days } \\
\text { when machine did not operate are also recorded under this head }\end{array}$ \\
\hline 9. & $\begin{array}{l}\text { Bypass for air filter } \\
\text { cleaning }\end{array}$ & $\begin{array}{l}\text { Many times machines lift hoods and create a bypass in mid of sweeping activity (stationed at one } \\
\text { point), increasing air turbulence to de-clog the suction nozzles and air filters. }\end{array}$ \\
\hline 10. & Break for tea/lunch & Time spent on lunch/tea breaks \\
\hline 11. & $\begin{array}{l}\text { Cleaning time of } \\
\text { filters(manual) during } \\
\text { dumping }\end{array}$ & $\begin{array}{l}\text { It has been observed in some locations the operating staff uses stick (bamboo) to manually clean } \\
\text { filters after dumping the collected road dust. The time spent under this activity is recorded under } \\
\text { this. }\end{array}$ \\
\hline 12. & $\begin{array}{l}\text { Waiting after } \\
\text { completing trip at } \\
\text { depot }\end{array}$ & $\begin{array}{l}\text { In case the designated route is completed or diesel allocated is exhausted and vehicles arrive back } \\
\text { to depot and balance time under the shift is recorded under this activity }\end{array}$ \\
\hline 13. & Standing idle & $\begin{array}{l}\text { If during a shift machines are standing idle, either due to some instruction/lack of information by } \\
\text { official, or due to non-availability of dumping location, the time spent by machine is recorded } \\
\text { under this head. }\end{array}$ \\
\hline 14. & $\begin{array}{l}\text { Washing of the } \\
\text { vehicle }\end{array}$ & Time spent on washing of vehicles during shift time is recorded under this activity. \\
\hline 15. & Traffic jam & Road traffic jams during the shift and are recorded under this head. \\
\hline
\end{tabular}

Keeping sample size based on statistical sampling method, which could lead to results with $>90 \%$ confidence levels, audits were designed. As a part of the audit reporting process, express memo identifying gaps in maintenance and operations of machines, with suggestions to increase outputs were shared with ULB officials (zone wise) on weekly basis to ascertain corrective actions in a timely manner and enhance effectiveness of these MRS operations.

For calculating sample size (n) for the number of audits to be undertaken every week Cochran's formula for finite population size was adopted [17].

Equation 1

$$
\mathrm{n}=\frac{\mathrm{n}^{\circ}}{1+\frac{\left(\mathrm{n}^{\circ}-1\right)}{\mathrm{N}}}
$$

Where,

$\mathrm{n}=$ sample size

$\mathrm{N}=$ population size $=144$

$n^{\circ}=\frac{Z^{2} p q}{e^{2}}$

level $=1.64$

$\mathrm{Z}=$ selected critical value of desired confidence

$\mathrm{p}=$ estimated proportion of an attribute that is

present in the population $=0.5$

$$
\begin{aligned}
& \mathrm{q}=1-\mathrm{p}=0.5 \\
& \mathrm{e}=\text { desired level of precision }=0.1
\end{aligned}
$$

The audits were initiated for SDMC in July 2018, and thereafter extended to North DMC, EDMC and NDMC areas. SDMC and North DMC have undergone 3 phases of audits till March 2020 and EDMC and NDMC have undergone one phase of audit. A phase of audit is its contractual duration, which is 18 weeks for North DMC and NDMC, and 26 weeks for EDMC and SDMC.

In ULBs where machines were operated in 2 shifts a day like EDMC, audits were undertaken in day and night shifts, alternatively on weekly basis. Whereas, in NDMC where 4 machines were operated in night shift also, one auditor use to audit only night shift operations. Overall, one auditor was made responsible to audit 2 machines in a shift, by physically verifying operations through a set detailed questionnaire. North DMC used to operate these machines for 10 hours in a day, during $3^{\text {rd }}$ phase (10-12 hours during $2^{\text {nd }}$ phase ), and EDMC had a contract for operating auxiliary engine for 08 hours a shift, running these machines in 1 shifts a day initially and thereafter from mid of October 2019 - January 2020 in 2 shifts, based on audit recommendations.

SDMC had their machines stationed in respective Central, Najafgarh, South, West and zones, EDMC and NDMC had their machines stationed at one central place. North DMC had 15 MRS (used for Rohini, Civil Lines, Karol Bagh, Sadar Paharganj and Keshavpuram zones) stationed at one central location and 3 machines, catering to Narela Zone at Narela itself. Centralized parking of these machines was useful for contractors and his team to effectively conduct maintenance and cleaning of machines during off shift hours.

As a part of the audit process, audit team were required to physically assess time spent on various activities, proper utilization of sprinkling and its effectiveness, nonsweeping related travels (dead mileage) of machines, appropriateness of sweeping, distance of dumping locations and appropriateness, and other reasons for getting off route/non sweeping activity. The sweeping time share was thereafter statistically analyzed to evaluate mean values, standard deviation, and best estimate of uncertainty in data. The data gathered as well as analyzed was shared with Nodal officer to prepare express memo, for submission to ULB officials thereafter. 
III. RESULTS AND DISCUSSIONS

Based on the Cochran's formula for finite population (equation 1), sample size for audit on a weekly basis were calculated. The number of audit samples and auditors required in each of the corporation were calculated and are shown in table 2 .

TABLE 2: SAMPLE SIZE OF AUDIT BASED ON SHIFTS OPERATED PER WEEK.

\begin{tabular}{|l|l|l|l|l|l|l|}
\hline ULB & $\begin{array}{l}\text { Number of } \\
\text { MRS } \\
\text { machines } \\
\text { operating }\end{array}$ & $\begin{array}{l}\text { Machines operating } \\
\text { double shift at start } \\
\text { of audit }\end{array}$ & $\begin{array}{l}\text { Shifts operated } \\
\text { per week with 06 } \\
\text { days operation }\end{array}$ & $\begin{array}{l}\text { Audit Required per equation 1 } \\
\text { as }\end{array}$ & $\begin{array}{l}\text { Audit Undertaken } \\
\text { for }>\mathbf{9 0 \%} \\
\text { confidence level }\end{array}$ & $\begin{array}{l}\text { Number of } \\
\text { auditors } \\
\text { deputed }\end{array}$ \\
\hline SDMC & 24 & $0 / 24$ & 144 & 46.05 & 48 & 4 \\
\hline NDMC & 07 & $04 / 07$ & 66 & 33.62 & 36 & 3 \\
\hline NORTH DMC & 18 & $0 / 18$ & 108 & 41.68 & 48 & 4 \\
\hline EDMC & 10 & $6 / 10$ & 33 & 36 & 3 \\
\hline
\end{tabular}

Traditionally, the road dust was swept manually in most of the main road areas. Depending upon the resources allocated by ULBs, some areas like, commercial, tourist areas, and important areas receive extensive service. However, most often the dust swept manually is left on the sides of these roads or areas which re-entered into environment as the traffic resumes during the day. A better alternative to address this problem is mechanized sweeping machine which helps in reducing the suspended particulate matter from these roads. These machines move slowly on the roads at an average speed of around $8 \mathrm{kms}$ per hour to brush on road sides and suck it up with the vacuum. The collected dust is disposed at designated place so does not reenter into environment again.

Overall, audits of 352 shifts of MRS operations conducted in Delhi, helped corporations increase their daily MRS outputs. With intentions and vision to bring these machines to deliver 40-50 kms sweeping per shift, gaps were identified. The major observation during audits; mean fraction of time spent on actual sweeping and kilometers swept helped corporations understand and devise ways to increase their outputs. Over the course of study it was observed that mean monthly sweeping time during a shift got increased from $28 \%$ to $66 \%$ (with a phase 3 average of $268.8 \pm 0.6$ minutes) in SDMC, $43 \%$ to $57 \%$ (by end of phase 2 ) and $54 \%$ (by end of phase 3 ) in North DMC (an average of $320.96 \pm 3.21$ minutes for phase 3 ), and $73 \%$ to $75 \%$ in EDMC. However, due to frequent breakdowns and operational issues NDMC recorded a negative progress with mean monthly sweeping time per shift reducing from $42 \%$ to $36 \%$ (with an overall average of $145.03 \pm 5.03$ minutes on sweeping). In terms of the outputs of MRS machines, SDMC recorded highest progress, the mean monthly sweeping which was $6 \mathrm{kms}$ per shift in August 2018 at the start of the shift, could be increased to $31.8 \mathrm{kms}$ per shift by January 2020, with audit findings and corrective actions by ULB officials. In North DMC, the mean monthly sweeping outputs were increased from $18.8 \mathrm{kms}$ per shift to $37 \mathrm{kms}$ per shift at end of phase 2 (with a $12 \mathrm{hrs}$ shift), and $30.2 \mathrm{kms}$ per shift by end of phase 3 (10 hrs shift). In EDMC, the mean monthly sweeping outputs were increased from $27.1 \mathrm{kms}$ per shift to $28.8 \mathrm{kms}$ per shift (monthly mean value of $57.6 \mathrm{kms}$ per day with double shift operation). Whereas, in NDMC due to maintenance and operational issues, leading to frequent breakdowns the mean monthly outputs were reduced from $22.2 \mathrm{kms} / \mathrm{shift}$ to $20.8 \mathrm{kms} / \mathrm{shift}$

\section{Mean Value of Shift Time Spent On Sweeping Activity}

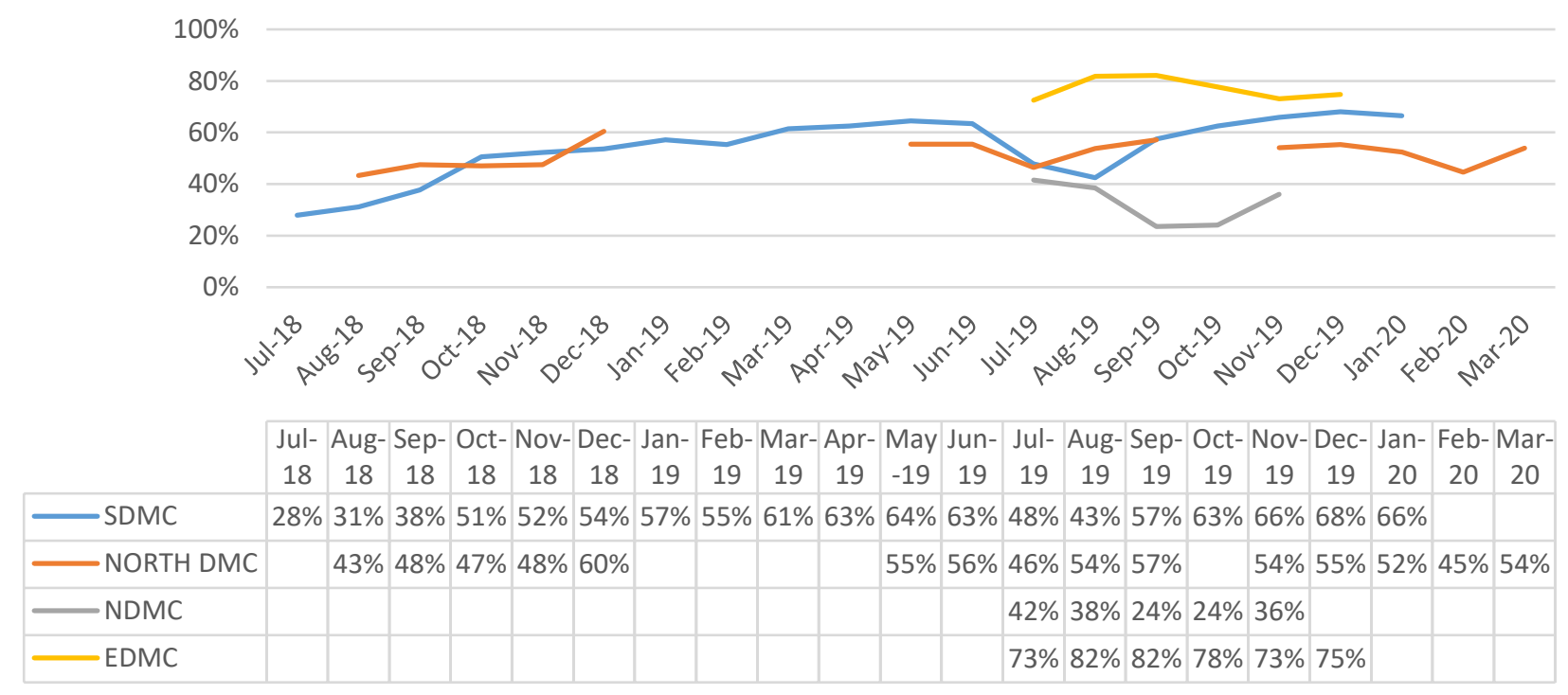

FIGURE 1: MEAN VALUE OF SHIFT TIME SPENT ON SWEEPING ACTIVITY 


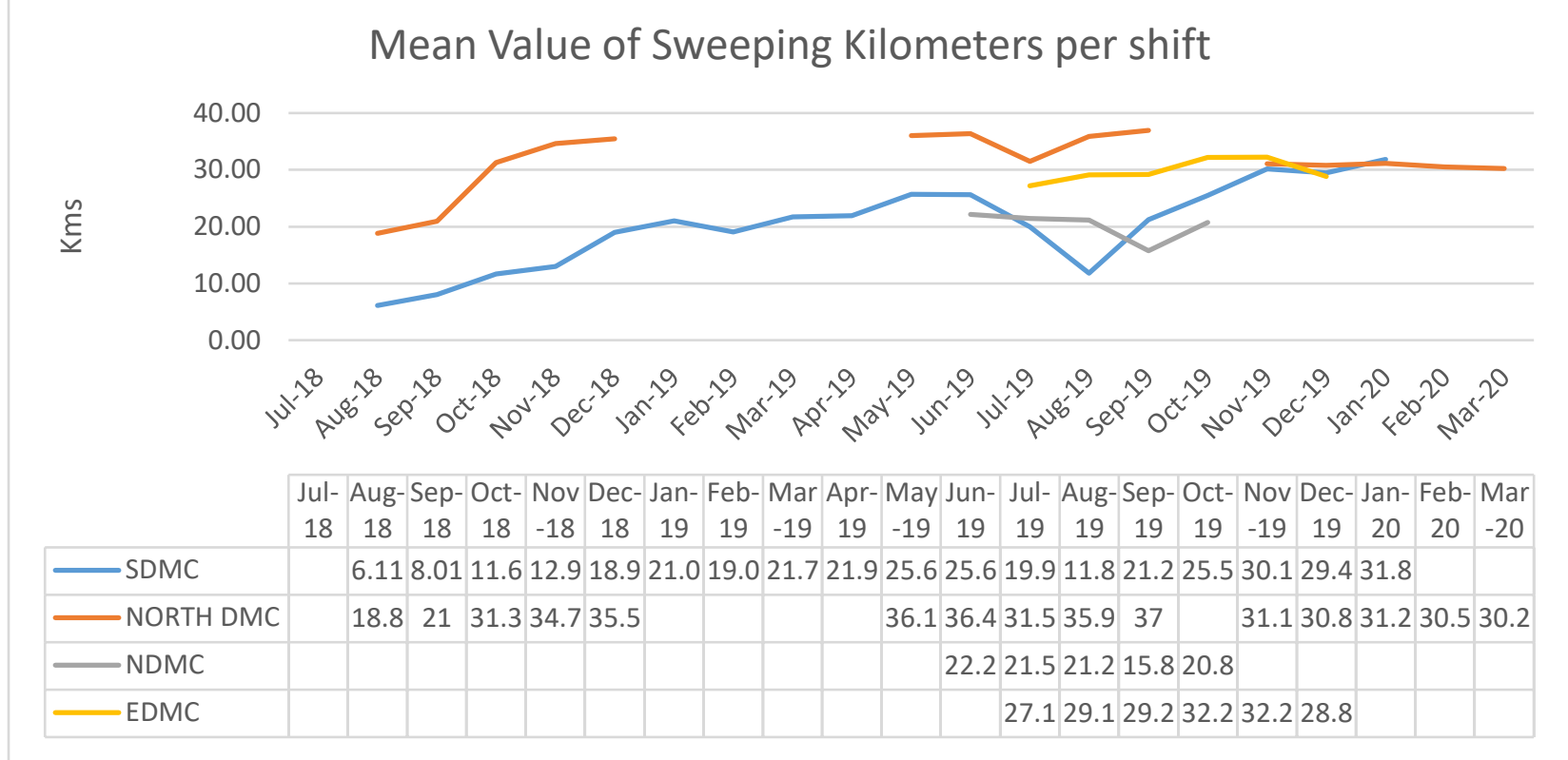

FIGURE 2: MEAN VALUE OF SWEEPING KILOMETERS PER SHIFT

To understand the time spent by MRS machines on nonsweeping activities, pie charts depicting on shift activities were prepared and shared with respective ULBs from time to time. The mean outputs on time spent by MRS machines on various activities, from the last phase of audits of all the four ULBs have been shown in figure 3. This figure clearly depicted that EDMC was putting maximum time of a shift on sweeping activity (with an average of $365.04 \pm 2.53$ minutes per shift). One of the reasons for this was contractual arrangement to run auxiliary engine for 8 hours a shift, as well as adequate planning by relevant department, with circular routes for MRS machines, diesel and water refilling by maintenance staff in non-shift hours, dumping of collected road dust at adjacent construction and demolition (C\&D) waste management facility (reducing dead mileage) and target setting for sweeping outputs as well as road dust loads

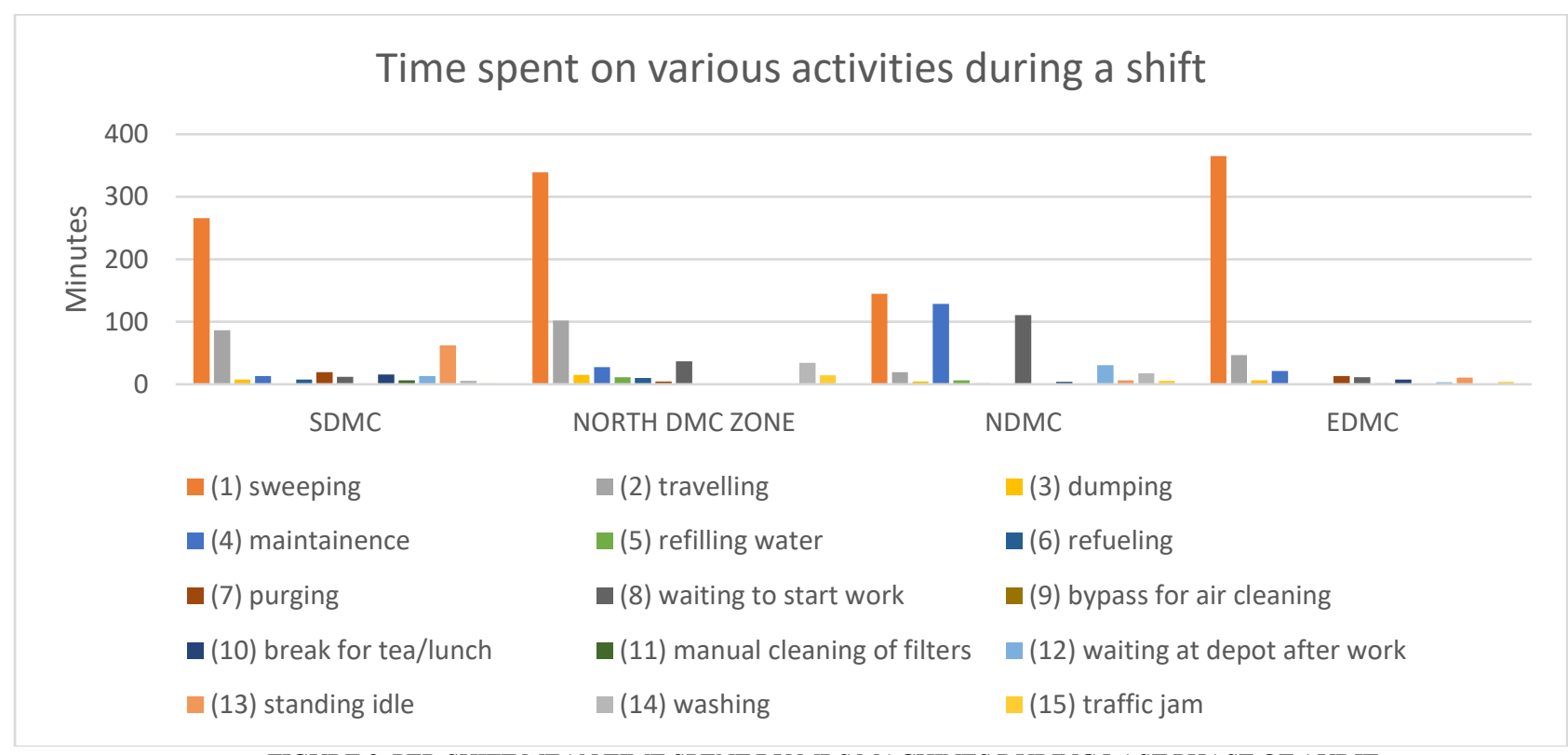

FIGURE 3: PER SHIFT MEAN TIME SPENT BY MRS MACHINES DURING LAST PHASE OF AUDIT

EDMC was the only ULB which had had collected road dust linked with $C \& D$ processing facility to reduce reentering of dust into environment. The average road dust collected per km of stretch swept in EDMC area was around $51.5 \mathrm{~kg}$.
In SDMC area road dust collected was dumped in lowlying areas, sometimes even far from route. In North DMC, collected dust loads were dumped either at Bhalaswa dumpsite or at dhalaos, based on type of machine used for sweeping. Wet sweeping machines used to dump collected road dust at nearby Dhalao only. In NDMC, a special area at 
parking site was created to collect the road dust, which was later dumped at low lying areas near Okhla landfill site. The arrangements which required machines to travel far off locations to dump the collected road dust lead to reduction of machine time spent on sweeping.

These machines are equipped with 1000 liters of water storage capacity, used for sprinkling. However, the misters associated with sprinklers were such that the water will get empty, even in half shift if properly operated. As a result, to reduce this loss of time in getting water refilled again, operators used to operate only side sprinklers, over the brush. There was a need for each corporation to provide water in mid of the shift to every sprinkling machine, and provide appropriate sprinkling tools (misters), which remained missing throughout the audits.

It was also observed that overall 59 machines required about $59 \mathrm{~m} 3$ of water each shift, which was sourced through ground water. There was a need to fulfil this requirement through treated wastewater, and conserve resources.

The reported diesel consumption was also high in MRS machines. In EDMC it was observed that front engine used to travel $03 \mathrm{kms}$ per liter and auxiliary engine consumed 9.7 liter per hour. Similarly, in North DMC same machines were found to consume 12.01 Liters per hour for auxiliary engine.
Possible reason for this deviation was revolution per minutes (rpm) of auxiliary engine, set by operators. The wet sweeping MRS machines which are medium sizes MRS trucks in North DMC, consumed around 4 liter of diesel per $\mathrm{kms}$ of running by front engine and 6.3 liter per hour for auxiliary engine. The derived fuel equations have been shown in table 3 .

As an outcome of these audits it was learnt that there was a need for well trained staff to operate these MRS machines, there is a need that such conditions are made a part of contracts both while procuring machines as well as awarding contracts to operate and maintain.

Usage of personal protective gears like uniform, helmet, reflective vest, eye gears, gloves and safety shoes and even ear muffs should be compulsory for helpers who often get down of these machines to facilitate brush operation. It was also learnt that only one helper should be provided along with one driver at each MRS machine and traffic signaling should be done with appropriate indications and alarms. Moreover, there should be motivational mechanisms built for MRS operators, to engage them as a team in helping improvise quality and quantity of sweeping.

TABLE 3: FUEL ECONOMY EQUATIONS FOR MRS MACHINES

\begin{tabular}{|l|l|l|l|l|}
\hline ULB & Type of MRS Machine & $\begin{array}{l}\text { Front Engine Fuel } \\
\text { Efficiency }(\mathbf{1} / \mathbf{y})(\mathbf{K m s} \\
\text { per Litre) }\end{array}$ & $\begin{array}{l}\text { Back Engine Fuel } \\
\text { Efficiency }(\mathbf{x})(\text { Litres per } \\
\text { hour) }\end{array}$ & Derived fuel Equation \\
\hline EDMC & Old MRS vehicle (Dry sweeping) & 3 & 9.7 & $7.99 \mathrm{x}+47.83 \mathrm{y}=93.42$ \\
\hline $\begin{array}{l}\text { North } \\
\text { DMC }\end{array}$ & Old MRS vehicle (Dry sweeping) & 3 & 12.01 & $9.31 \mathrm{x}+93.49 \mathrm{y}=142.95$ \\
\hline $\begin{array}{l}\text { North } \\
\text { DMC }\end{array}$ & New MRS vehicles (wet sweeping) & 4 & 6.3 & $8.30 \mathrm{x}+71.01 \mathrm{y}=75.98$ \\
\hline
\end{tabular}

The road dust collected should also be properly managed via $C \& D$ processing plants located in Delhi and should not be allowed to re-enter into environment, or utilize precious landfill volumes of the city.

ULBs should also take care that no extra mile is spent to get fuel and water for these machines, or even for dumping the collected road dust. Appropriate arrangements should be made to support utilization of these machines for sweeping activities, as far as possible. It should also be mandated that all the 4 stretches of a road should be taken simultaneously and at desired frequency.

Further, all 4 corporations had different contractual arrangements and neither one had payments of contractors linked with outputs and quality of sweeping. It was also identified that few operating staff members used to avoid usage of central brush, to prolong its usage, which resulted in ineffective utilization of machine.

Sanitation staff and supervisors at all the 4 ULBs were responsible to verify utilization of MRS machines, but due to odd hours of operation and vast coverage by these machines, their monitoring remained questionable. There is a need to implement a more robust mechanism which can be monitored offsite and reported instantly.

It was also felt that ULBs should take care that such machines intended to collect road dust, have adequate comfort for driver and helper staff and that cabins of these machines are dust free and air conditioned.

\section{CONCLUSION}

For better understanding, cumulative outputs of MRS machine operations are summarised in table 4 .

TABLE 4: OVERALL OUTPUTS OF MRS OPERATIONS IN DELHI

\begin{tabular}{|l|l|l|l|}
\hline Urban Local Body & Number of MRS & $\begin{array}{l}\text { Average sweeping (Kms) } \\
\text { /shift }\end{array}$ & $\begin{array}{l}\text { Double shift Operation status at end of } \\
\text { final audit phase }\end{array}$ \\
\hline SDMC & 24 & 22.91 & $0 / 24$ \\
\hline New Delhi Municipal Council & 07 & 19.59 & $04 / 07$ \\
\hline North DMC & 18 & 32.6 & $0 / 18$ \\
\hline East DMC & 10 & 29.56 & $10 / 10$ \\
\hline TOTAL/Average & 59 & 26.17 & $24 \%$ \\
\hline
\end{tabular}


These studies depict that ULBs of Delhi only puts $24 \%$ of its machines for double shift operations and on an average a machine sweeps around $26.17 \mathrm{kms}$ per shift. i.e 1943 kilometers of road stretch every day. Delhi has $4400 \mathrm{kms}$ of road stretch which can be swept by these machines. Hence just by enhancing the outputs of these machines to 74.57 $\mathrm{kms}$ per day (i.e $37 \mathrm{kms} / \mathrm{shift}$ and double shift operations), all $30 \mathrm{~m}$ right of way roads can be effectively catered. There is a need for all ULBs to streamline their MRS operations with inbuilt MRVs and better operation.

There is also a need to improvise the GPS tracking systems with procedures to track sweeping brush operations, proper sprinkler utilization and constant videography for monitoring the effectiveness of sweeping. This should be accompanied by physical verification of sweeping conducted in particular route, which is to be linked with operator's payment. Thus there is a need to establish linkage of contracts with outputs and effectiveness of sweeping operation. Further, since these are special machines and require spares which are not easily available in market, with ULBs maintaining these machines, they remain on breakdown for approvals which take time in their process. Hiring these machines on contractual arrangements, with operations, maintenance and ownership of these machines with private operators can reduce burdens as well as enhance outputs of MRS machines, though may be required for longer durations to derive feasibility for private operators. Such contractual arrangements can be target based, both in terms of quantity and quality of sweeping.

Mechanization and automations are the concepts, all ULBs should be ready to implement. However, appropriate monitoring and verification systems are must to have optimum utilization and effectiveness.

\section{ACKNOWLEDGE:}

We acknowledge EDMC, SDMC, NDMC and NorthDMC for engaging TERI to audit their mechanised road sweeping operations. We also acknowledge Mr Dilshad Ahmad and $\mathrm{Mr}$ Nirbhay $\mathrm{Kr}$ Singh for assisting us in literature search.

\section{REFERENCE}

[1] MoEFCC, "NATIONAL CLEAN AIR PROGRAMME," Ministry of Environment, Forest \& Climate Change, New Delhi, 2019.
[2] World Health Organization, Global Health Observatory data, World Health Organization, 2018.

[3] World Health Organization, "Newsroom: fact sheets:detail Ambient (outdoor) air pollution," 2 May 2018. [Online]. Available: https://www.who.int/news-room/fact-sheets/detail/ambient(outdoor)-air-quality-and-health. [Accessed 18 May 2020].

[4] World Health Organization, "WHO Air quality guidelines for particulate matter, ozone, nitrogen dioxide and sulfur dioxide," World Health Organization Press, Geneva, 2005.

[5] Times News Network, "News: City News: Delhi News:14 of world's 15 most polluted cities in India," 2 May 2018. [Online]. Available: https://timesofindia.indiatimes.com/city/delhi/14-ofworlds-15-most-polluted-cities-inindia/articleshow/63993356.cms. [Accessed 18 May 2020].

[6] Central Pollution Control Board, "Air Pollution in Delhi (An Analytical Study)," ENVIS Centre on Control of Pollution Water, Air and Noise, New Delhi, 2010.

[7] Indian Institute of Kanpur, "Comprehensive Study on Air Pollution and Green House Gases (GHGs) in Delhi," Government of National Capital Territory of Delhi, New Delhi, 2016.

[8] The Automotive Research Association of India;The Energy and Resources Institute, "Source Apportionment of PM2.5 \& PM10 of Delhi NCR for Identification of Major Sources," The Energy and Resources Institute, New Delhi, 2018.

[9] AIRUSE, "REVIEW OF IMPACT OF STREET CLEANING ON PM10 AND PM2.5 CONCENTRATIONS IN NORTHERN AND CENTRAL EUROPE," AIRUSE, 2016.

[10] IQAir, "2019 World Air Quality Report -Region and City PM2.5 Ranking," IQAir, Switzerland, 2020.

[11] R. Kuehl, M. Marti and J. Schilling, "Resource for Implementing a Street Sweeping Best Practice," 2008.

[12] Times News Network, "New: City News: Indore news: Air in Indore cleaner than a year ago as pollutants down by 5\%," 27 February 2020. [Online]. Available: https://timesofindia.indiatimes.com/city/indore/air-in-indorecleaner-than-a-year-ago-as-pollutants-down-by5/articleshow/74325874.cms. [Accessed 18 May 2020].

[13] Indore Municipal Corporation "https://cdn.cseindia.org/docs/photogallery/slideshows/06_20171 212_IMC-SWM-Final-Indore.pdf," 2017. [Online]. Available: https://cdn.cseindia.org/docs/photogallery/slideshows/06_201712 12_IMC-SWM-Final-Indore.pdf. [Accessed 18 May 2020].

[14] Transperancy Market Research, "Street Sweepers Market," March 2020. [Online]. Available: https://www.transparencymarketresearch.com/street-sweepersmarket.html. [Accessed 18 May 2020].

[15] Central Public Health and Environmental Orgnisation, "Municipal Soid Waste Management Manual," Central Public Health and Environmental Orgnisation(CPHEEO), New Delhi, 2016.

[16] Department of Urban Development, Government of Delhi, "City development Plan, Chapter-11," Department of Urban Development, Government of Delhi, New Delhi, 2006.

[17] W. G. COCHRAN, Sampling Techniques, Third E dition, John Wiley \& Sons, 1977. 